\title{
A estrutura do segmento oeste da Serra do Curral, Quadrilátero Ferrífero, e o controle tectônico das acumulações compactas de alto teor em Fe
}

The structure of western Serra do Curral, Quadrilátero Ferrifero, and tectonic control of the high-grade iron hard bodies

\author{
Julio Carlos Destro Sanglard ${ }^{1}$, Carlos Alberto Rosière², João Orestes Schneider Santos ${ }^{3}$, \\ Neil Jesse McNaughton ${ }^{4}$, lan Robert Fletcher ${ }^{4}$ \\ ${ }^{1}$ Escola de Ciências e Tecnologia de Exploração e Produção, Universidade PETROBRAS, Rua Ulisses Guimarães 565 - \\ Cidade Nova, CEP 20211-225, Rio de Janeiro, RJ, BR (jcsanglard@ymail.com) \\ ${ }^{2}$ Instituto de Geociências, Universidade Federal de Minas Gerais - UFMG, Belo Horizonte, MG, BR (crosiere@gmail.com.br) \\ ${ }^{3}$ Centre for Exploration Targeting, University of Western Australia, Perth, AU (orestes.santos@bigpond.com) \\ ${ }^{4}$ Curtin University of Technology, Perth, AU (n.mcnaughton@curtin.edu.au; i.fletcher@curtin.edu.au)
}

Recebido em 26 de abril de 2013; aceito em 11 de dezembro de 2013

\begin{abstract}
Resumo
O segmento oeste da Serra do Curral, Quadrilátero Ferrífero, representa a exposição parcial de um sinclinal vergente para NNW - Sinclinal Piedade. As dobras parasíticas dessa estrutura regional foram denominadas $\mathrm{B}_{1 \mathrm{~A}}$ e estão redobradas por dobras $\mathrm{B}_{1 \mathrm{~B}}$, também vergentes para NNW. Ambas são de direção ENE-WSW, acilíndricas e configuram um padrão de superposição semelhante ao Tipo 3 de Ramsay. Esse redobramento ocorre em caráter de deformação progressiva e junto com falhas inversas de alto ângulo e de mesma direção que controlam a ocorrência de acumulações magnetítica-martíticas de alto teor ( $>64 \% \mathrm{Fe})$ de tamanho médio ( $100 \mathrm{Mt})$. Sobre essas estruturas, estão desenvolvidas dobras de direção NNW-SSE com vergência para WSW (dobras $\mathrm{B}_{2}$ ). Estas se limitam aos flancos das dobras $\mathrm{B}_{1}$ e configuram um padrão de superposição do tipo abbuting fold. A idade obtida por datação U/Pb SHRIMP em grãos de monazita que ocorrem em equilíbrio textural com os óxidos de ferro das acumulações de alto teor é $2034 \pm 11$ Ma. Essa idade corresponde ao timing de formação desses corpos e indica que o processo de mineralização é contemporâneo ao pico metamórfico regional do Quadrilátero Ferrífero.
\end{abstract}

Palavras-chave: Geologia estrutural; Serra do Curral; Minério de ferro; Quadrilátero Ferrífero.

\begin{abstract}
The structure of western Serra do Curral, Quadrilátero Ferrífero, represents the partial exposure of a syncline that verges to NNW - Piedade Syncline. This regional structure has parasitic folds denominated as $B_{1 A}$ which are refolded by folds $B_{1 B}$ that also have vergence to NNW. Both of them have ENE-WSW direction, are non-cylindrical folds and configure an interference pattern that is similar to Type 3 from Ramsay. This refolding occur during progressive deformation. The occurrence of highgrade magnetitic-martitic accumulation $(>64 \% \mathrm{Fe})$ of medium size $(\sim 100 \mathrm{Mt})$ is controlled by the combination of these folds and high angle thrust fault, both with the same direction. Above these structures, there is a development of folds with NNWSSE direction and WSW vergence ( $\mathrm{B}_{2}$ folds). These folds are restricted to the $\mathrm{B}_{1}$ limbs and they configure an interference pattern named "abbuting fold". The age obtained by U/Pb SHRIMP on monazite grains is $2034 \pm 11 \mathrm{Ma}$. The monazite grains occur on textural balance with the iron oxide from high-grade accumulations. This age corresponds to the formation timing of the high-grade bodies and suggests that the mineralization process is contemporary to the regional metamorphic peak of Quadrilátero Ferrífero.
\end{abstract}

Keywords: Structural geology; Serra do Curral; Iron ore; Quadrilátero Ferrífero. 


\section{INTRODUÇÃO}

A Serra do Curral estende-se cerca de $100 \mathrm{~km}$ na direção NE-SW e marca o limite norte do distrito minerário do Quadrilátero Ferrífero $(\mathrm{QF})$. Em termos estruturais, ela representa, em sua maior parte, o flanco invertido de um sinclinal vergente para NNW, o Sinclinal Piedade. O flanco normal dessa estrutura aflora nas suas extremidades nordeste e sudoeste (Alves, 1961; Romano, 1989).

A área abordada neste trabalho compreende o segmento da Serra do Curral com aproximadamente $30 \mathrm{~km}$ de extensão, localizado a oeste do Rio Paraopeba (Figura 1). Esse segmento apresenta características distintas da região desse mesmo elemento geomorfológico a leste do Sinclinal da Moeda (Rosière et al., 2008).

Depósitos de minério de ferro de alto teor $(\sim 100 \mathrm{Mt})$ e veios magnetíticos/martíticos maciços com ca. $66 \%$ de
Fe ocorrem nessa região. Essas acumulações são compostas predominantemente por magnetita (até 70\%) parcialmente oxidada em kenomagnetita, maghemita e martita e por hematita granular a lamelar (Rosière et al., 2008). A baixa deformação interna sofrida pelas formações ferríferas, a preservação das feições primárias, o tamanho relativamente pequeno dos corpos de minério e a ausência de grandes zonas de cisalhamento especularíticas facilitam a compreensão do controle estrutural dos depósitos de ferro nessa região do $Q F$.

\section{CONTEXTUALIZAÇÃO GEOLÓGICA REGIONAL}

$\mathrm{O} Q \mathrm{QF}$ é um distrito minerário de ferro e ouro localizado na borda sudeste do Cráton do São Francisco (Almeida, 1977) onde rochas metassedimentares do Supergrupo Minas afloram

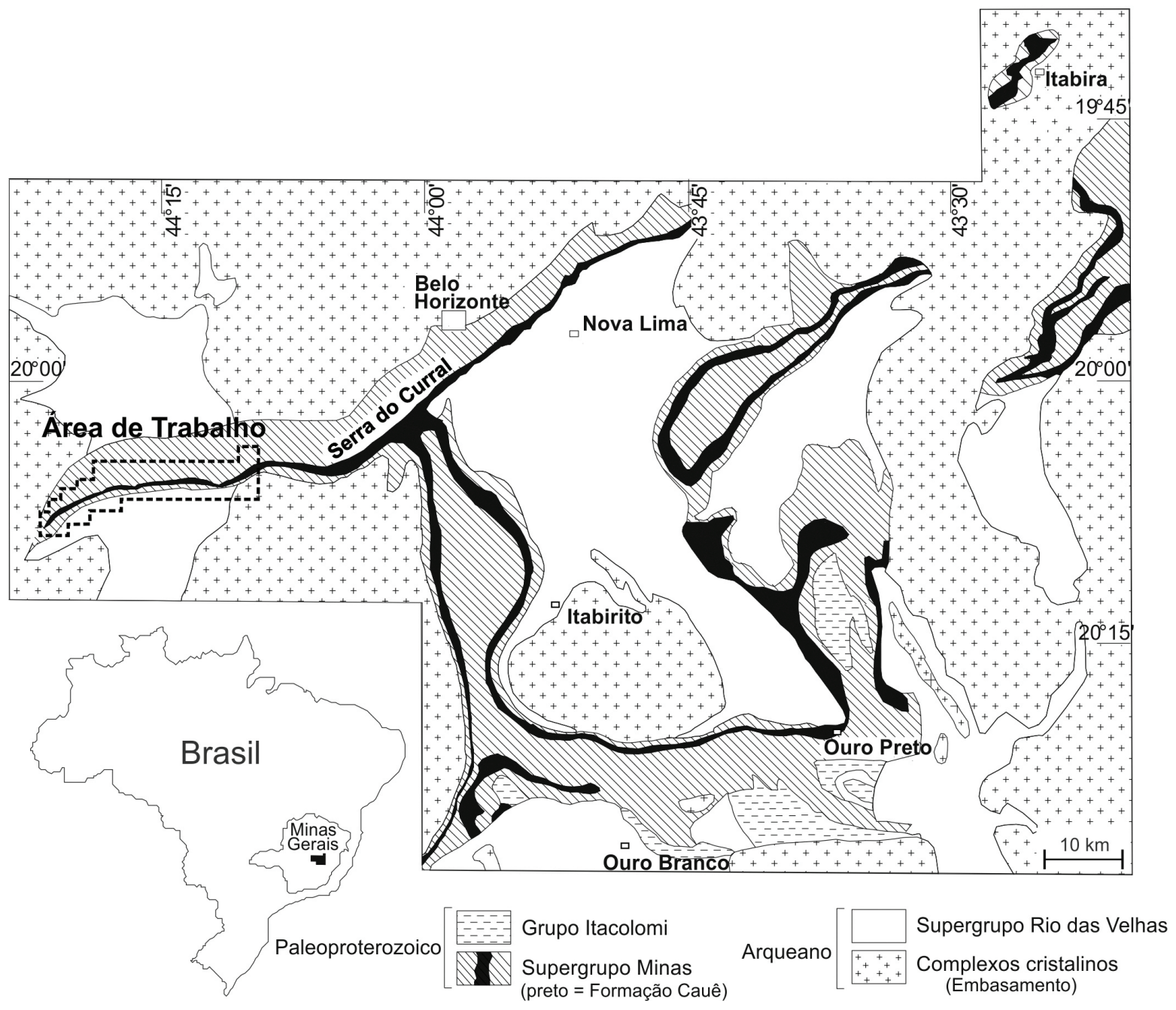

Mapa editado de Spier et al. (2008).

Figura 1. Localização do segmento oeste da Serra do Curral em mapa geológico simplificado do Quadrilátero Ferrífero. 
em quilhas sinclinais limitadas por domos gnáissicos e terrenos greenstones (Dorr II, 1969; Marshak et al., 1997). Os domos são complexos granito-gnáissico-migmatíticos do tipo TTG correspondentes a terrenos neoarqueanos que resultaram do retrabalhamento de crosta mais antiga (Carneiro, 1992; Teixeira et al., 1996; Noce et al., 1998). O terreno greenstone corresponde ao Supergrupo Rio das Velhas (Loczy e Ladeira, 1976), sequência metavulcanossedimentar datada em 2776 Ma (U/Pb em zircão de rochas vulcânicas félsicas por Machado et al., 1992). A sedimentação/magmatismo dessa unidade foi contemporânea à intrusão de granitoides nos complexos do tipo TTG, e o metamorfismo desses terrenos, entre 2780 $2700 \mathrm{Ma}$, foi atribuído ao Evento Tectonotermal Rio das Velhas (Carneiro et al., 1998).

O Supergrupo Minas (Sg. Minas), assim denominado por Pflug e Renger (1973), ocorre em discordância sobre o Sg. Rio das Velhas e complexos TTG (Dorr II, 1969). Segundo Chemale Jr. et al. (1994), é uma sequência depositada em bacia intracratônica ou, conforme Alkmim e Marshak (1998), em ambiente plataformal de margem passiva. Ávila et al. (2012) propuseram que anfibolitos aflorantes no sul do Cráton do São Francisco representem produtos metamórficos de basaltos de crosta oceânica dessa bacia e, assim, corroboram a proposta de Alkmim e Marshak (1998).

Da base para o topo, o Sg. Minas é composto pelos grupos Caraça, Itabira, Piracicaba e Sabará (Dorr II et al., 1957). O Grupo Caraça marca o início da sedimentação na bacia e possui metaconglomerados auríferos e quartzitos (Formação Moeda; Wallace, 1958), que gradam para metapelitos plataformais da Formação Batatal (Maxwell, 1958). Sobreposto ao Grupo Caraça e em contato transicional, está o Grupo Itabira, que representa o maior período de sedimentação química plataformal da bacia, subdividido em Formação Cauê (Dorr II, 1958a) e Formação Gandarela (Dorr II, 1958b). A primeira é a basal e composta predominantemente por itabiritos (correspondente ao produto metamórfico de formações ferríferas bandadas - BIF). A espessura da Fm. Cauê é da ordem de 250 a 300 m e é nessa unidade que ocorrem todos os grandes depósitos de ferro de alto teor do QF. A Fm. Gandarela se sobrepõe à $\mathrm{Fm}$. Cauê em contato transicional e é composta predominantemente por mármores e metadolomitos.

O Grupo Piracicaba tem sua base marcada por discordância erosiva e representa uma sequência predominantemente clástica. É formalmente subdivido da base para o topo nas formações Cercadinho, Fecho do Funil, Taboões e Barreiro (Pomerene, 1958a; Simmons, 1968; Pomerene, 1958b, 1958c; Gair, 1958, respectivamente). De acordo com Renger et al. (1994), sua deposição ocorreu após emersão e erosão de parte do Grupo Itabira. De modo geral, há uma granodecrescência dos metaconglomerados e metarenitos da base da Fm. Cercadinho para os metapelitos, localmente carbonosos, da Fm. Barreiro (Dorr II, 1969).
O Grupo Sabará (Gair, 1958; Barbosa, 1968; Renger et al., 1994) é a unidade de topo do Sg. Minas e pode alcançar espessura de 3-3,5 km (Dorr II, 1969). Sua variedade litológica com os correspondentes metamórficos de pelitos, grauvacas, conglomerados, arenitos, tufos, rochas vulcânicas máficas e ácidas e chert ferruginoso/BIF é interpretada como preenchimento de bacia foreland de orógeno paleoproterozoico (Alkmim e Marshak, 1998).

Dois tipos de metamorfismo foram reconhecidos por Herz (1978) nas rochas do Sg. Minas. Um é regional e o outro, localizado nas proximidades dos complexos do tipo TTG. A partir da variação textural e mudanças químicas/mineralógicas em metapelitos e itabirito da Fm. Cauê, Pires (1995) mostrou que há aumento do grau metamórfico de NW para SE/E no QF. A ocorrência de metamorfismo de contato ao redor de rochas do embasamento cristalino também foi documentada por Jordt-Evangelista et al. (1992) nas rochas do Grupo Sabará na cidade de Ibirité. Silimanita-granadamoscovita xisto dessa mesma região forneceu idade $\mathrm{Sm} /$ $\mathrm{Nd}$ de $2095 \pm 65 \mathrm{Ma}$ (Marshak et al., 1997). Em paralelo ao acréscimo do grau metamórfico, há aumento do grau de deformação interna das rochas e, a partir dessa variação, Rosière et al. (2001) dividiram a região do QF em dois domínios estruturais: o domínio de baixa deformação a oeste, onde estruturas primárias das BIFs (mesobandamento e microbandamento) estão preservadas nos itabiritos, e o de alta deformação a leste, marcado pela presença generalizada de trama xistosa especularítica (Rosière et al., 2001). Dessa forma, o segmento oeste da Serra do Curral insere-se na zona de baixa deformação e está na região onde o Sg. Minas registra o mais baixo grau metamórfico - zona da clorita para os metapelitos e grunerita para o itabirito (Pires, 1995).

$\mathrm{O}$ acervo geocronológico existente para o QF permite limitar a deposição do Sg. Minas entre 2580 e $2050 \mathrm{Ma}$ (Renger et al., 1994). Datação $\mathrm{Pb} / \mathrm{Pb}$ apresentada por Babinski et al. (1995) forneceu idade de $2420 \pm 19 \mathrm{Ma}$ para carbonato estromatolítico da Fm. Gandarela e foi assumida como idade de deposição. Datações K/Ar em anfibólio, biotita e moscovita mostram que houve abertura desse sistema isotópico durante o Paleoproterozoico tal como no Neoproterozoico, registrando, assim, a influência dos ciclos orogênicos Transamazônico e Brasiliano na região do QF (Noce, 2000; Endo e Machado, 2002). Segundo Noce et al. (1998), o pico metamórfico da Orogênese Transamazônica na região do QF ocorreu em $2041 \pm 5$ Ma.

Diferentes modelos de evolução estrutural posteriores à deposição do $\mathrm{Sg}$. Minas já foram propostos para a região do QF (e.g. Dorr II, 1969; Ladeira e Viveiros, 1984; Chemale Jr. et al., 1994; Endo, 1997; Alkmim e Marshak, 1998; Hippertt e Davis, 2000). Embora diferentes, é consensual que a história deformacional do QF é policíclica com influência da orogenia Transamazônica e Brasiliana. 
O primeiro acervo de estruturas compressivas tem orientação NE-SW e desenvolveu-se durante compressão vergente para NNW no foreland de um orógeno Transamazônico (Alkmim e Marshak, 1998). Sobre essas estruturas, há o desenvolvimento de acervo estrutural de direção NW-SE. De acordo com Dalstra e Rosière (2008) e Rosière et al. (2008), essas estruturas teriam se formado imediatamente após o desenvolvimento das anteriores no mesmo ciclo orogênico Transamazônico. A formação de zonas de cisalhamento normais que bordejam os domos granito-gnáissicos teriam se desenvolvido durante o colapso desse orógeno (Marshak et al., 1997; Alkmim e Marshak, 1998).

A estrutura da Serra do Curral é o maior exemplo do acervo de estruturas vergentes para NNW e corresponde, de forma geral, a um homoclinal de direção geral NE-SW, com aproximadamente $100 \mathrm{~km}$ de extensão (Figura 1). Ao longo de praticamente toda sua extensão, as unidades do Sg. Minas estão invertidas com mergulho das camadas predominantemente para SE. Na sua extremidade NE, as unidades se repetem a norte em posição normal e configuram a geometria de um sinclinal (Sinclinal Piedade, conforme Alves, 1961). Simmons (1968) também caracterizou a serra como flanco invertido desse sinclinal parcialmente preservado a norte, e Romano (1989) descreveu outra parte do flanco normal dessa estrutura na região sudoeste da serra, nos arredores do município de Serra Azul. Pomerene (1964), Pires (1979), Alkmim et al. (1996) e Endo (1997) atribuíram o homoclinal da Serra do Curral não só ao flanco do sinclinal como também a um anticlinal a sul, preservado apenas na junção com o Sinclinal Moeda.

As acumulações de ferro compactas (ou "duras") que ocorrem no QF resultam de processo hipogênico em que fluidos hidrotermais lixiviam a ganga (principalmente quartzo + carbonato dos itabiritos) e também remobilizam o ferro (Rosière et al., 2008). Nesse sentido, as falhas atuam como conduto para os fluidos, enquanto as zonas de charneira são locais favoráveis à interação deles com o itabirito, levando à formação hipogênica de acumulações de alto teor em Fe (Dalstra e Rosière, 2008; Rosière et al., 2008, 2013b).

\section{ARCABOUÇO ESTRUTURAL}

\section{Elementos estruturais}

Os elementos planares e lineares utilizados para subsidiar a análise estrutural no segmento oeste da Serra do Curral são: $\mathrm{S}_{0}$-acamamento das rochas siliciclásticas e laminação do itabirito marcada pela intercalação de lâminas de quartzo, hematita e/ou magnetita, carbonato e anfibólio (Figura 2A),
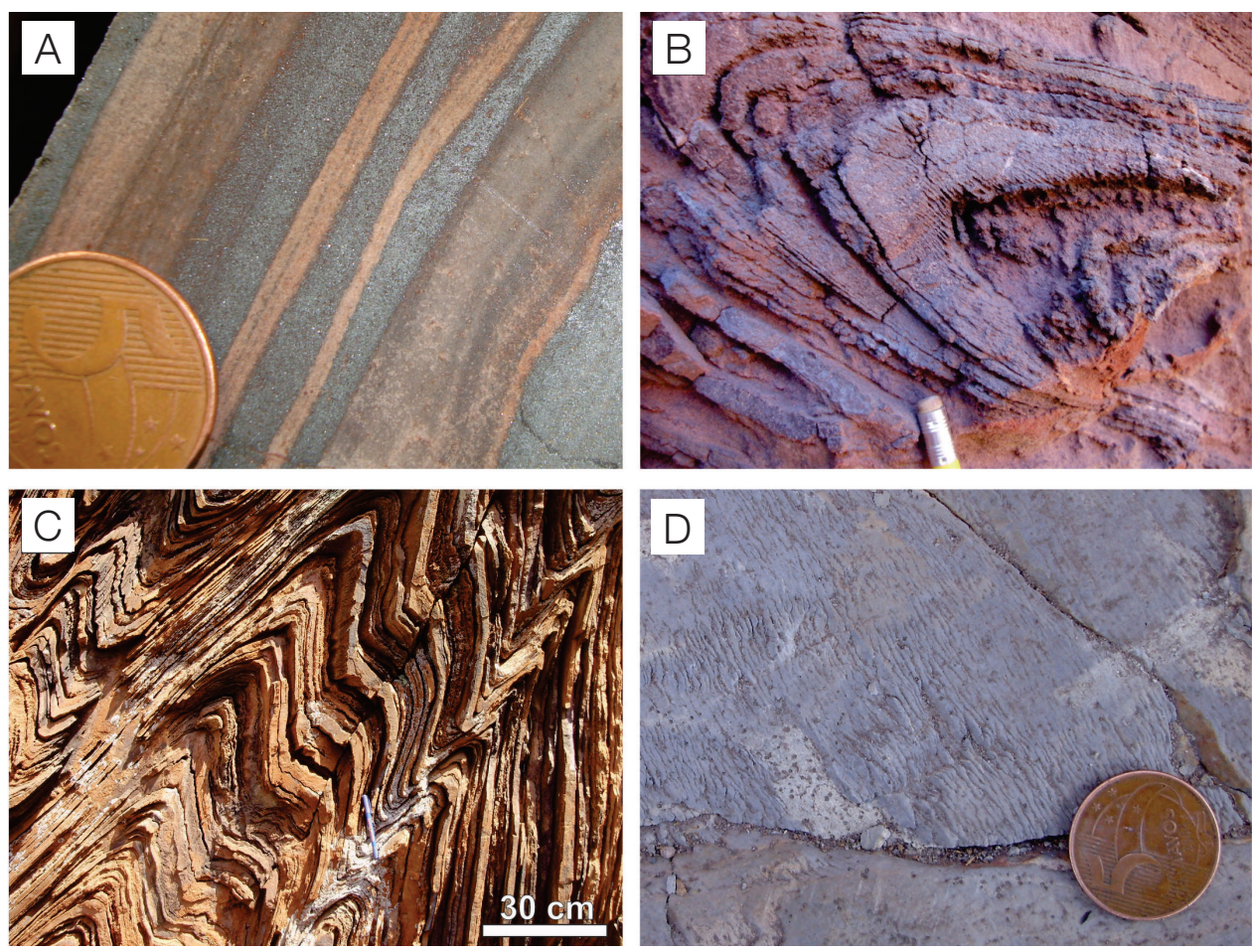

Figura 2. (A) Bandamento do itabirito definido pela intercalação de lâminas quartzosas e de óxido de ferro. Notar o microbandamento nas lâminas silicosas; (B) foliação planoaxial S1 em dobra isoclinal no itabirito; (C) exemplo de dobras parasíticas em zona de charneira com morfologia "M"; (D) eixos de crenulação e lineação de interseção de $S_{2}$ com $S_{1}$ em filito. 
além de feições sedimentares/diagenéticas tais como estruturas lenticulares de compactação; $\mathrm{S}_{1}$ e $\mathrm{S}_{2}$ - clivagem ardosiana e clivagem de crenulação, respectivamente, definidas pela orientação de lamelas de hematita/especularita e de anfibólio (cummingtonita-grunerita) no itabirito (Figura 2B) ou clorita e sericita nos filitos e quartzitos; plano axial e eixo de dobras $\mathrm{B}_{1}$ e $\mathrm{B}_{2}$ (Figura 2C); lineação de interseção entre $\mathrm{S}_{1}$ e $\mathrm{S}_{0}, \mathrm{~S}_{2}$ e $\mathrm{S}_{1}$ e $\mathrm{S}_{2}$ com $\mathrm{S}_{0}$ (Figura 2D).

As foliações $S_{1}$ e $S_{2}$ são paralelas aos planos axiais das dobras $\mathrm{B}_{1}$ e $\mathrm{B}_{2}$, respectivamente, e serão tratadas unificadamente como superfícies $\mathrm{S}_{1}$ e $\mathrm{S}_{2}$ nos estereogramas. Da mesma forma, as lineações de interseção de $\mathrm{S}_{1}$ com $\mathrm{S}_{0}$ e de $\mathrm{S}_{2}$ com $\mathrm{S}_{1}$ e $\mathrm{S}_{0}$ são, respectivamente, paralelas aos eixos das dobras $\mathrm{B}_{1}$ e $\mathrm{B}_{2}$ e também serão tratadas em conjunto.

As dobras $B_{1}$ são de direção ENE-WSW, harmônicas ou desarmônicas, e resultam de dobramento em que o deslizamento flexural é um mecanismo atuante e causa a abertura de espaços nas zonas de charneira. Esses locais são zonas de baixa pressão favoráveis à percolação de fluidos e, se preenchidos por alguma fase mineral, constituem saddle reefs. Caso permaneçam vazias, ocorre o colapso da charneira (Ramsay e Huber, 1987; Figura 3). A Figura 3 apresenta exemplos de saddle reefs de quartzo e charneira colapsada em itabirito quartzoso da Fm. Cauê. Dobras harmônicas têm perfil aproximadamente similar, com o desenvolvimento da foliação planoaxial (Figuras 2B e 2C), provavelmente por efeito de achatamento (flattening).

As dobras $B_{1}$ podem ser subdivididas em dois conjuntos: dobras $\mathrm{B}_{1 \mathrm{~A}}$ e $\mathrm{B}_{1 \mathrm{~B}}$. As estruturas $\mathrm{B}_{1 \mathrm{~A}}$ são centimétricas a métricas, isoclinais a apertadas, geralmente acilíndricas com eixos fortemente curvilíneos. Em visada para leste, apresentam-se predominantemente com geometria " $Z$ ". Formas em "S" ou mesmo em "M" também ocorrem, mas são menos frequentes e menores (Figura 4A). As dobras $B_{1 B}$ são métricas a decamétricas, fechadas a isoclinais e, como $\mathrm{B}_{1 \mathrm{~A}}$, são harmônicas ou desarmônicas e acilíndricas. Sua geometria mais comum em visada para leste é "S" (Figura 4B). Essas dobras redobram as dobras $\mathrm{B}_{1 \mathrm{~A}}$ e os elementos geométricos (plano axial e eixo) de ambas são subparalelos (Figura 4C) e serão tratados em conjunto nos estereogramas. Nas zonas de charneira de $\mathrm{B}_{1 \mathrm{~B}}$, é clara a relação de superposição sobre $B_{1 \mathrm{~A}}$ (Figura $\left.4 \mathrm{C}\right)$ e a relação entre elas aproxima-se da superposição do Tipo 3 de Ramsay (1967); no entanto, as duas gerações são apertadas a isoclinais.

Sobre as dobras $\mathrm{B}_{1}$, ocorrem com direção ortogonal ou alta obliquidade as dobras $\mathrm{B}_{2}$. Estas possuem dimensões centimétricas a métricas com geometria aberta a fechada. Sua ocorrência é discreta e limita-se aos flancos das dobras $\mathrm{B}_{1}$ (Figura 5) ao longo do segmento oeste da Serra do Curral. Esse padrão de superposição em que a segunda geração de dobra desaparece em direção à charneira da anterior foi denominado de padrão abutting fold por Simón (2004) em relação de superposição semelhante na região leste da cordilheira Ibérica, Espanha.

\section{Setores estruturais}

A partir da variação da atitude dos elementos estruturais, o segmento oeste da Serra do Curral foi dividido em três setores: Oeste, Central e Leste. Na Figura 6, estão indicados cada um desses setores junto com os estereogramas dos elementos estruturais.

Da extremidade oeste até o Rio Paraopeba, o mergulho das unidades basais do Sg. Minas (grupos Caraça e Itabira) aumenta progressivamente, saindo de camadas invertidas com mergulho moderado para SE, até posição normal com alto mergulho para NW na região da Mina Esperança (seções A, B e C da Figura 7). As unidades superiores do Sg. Minas expostas na vertente norte possuem mergulho baixo a moderado para $\mathrm{S}$ e $\mathrm{SE}$ ao longo de toda a serra.

\section{Setor Oeste}

Neste setor, a serra está alinhada segundo N60E e toda a sequência do $\mathrm{Sg}$. Minas está invertida com mergulho médio de $40^{\circ}$ para SE enquanto os metapelitos do Grupo Nova Lima repousam sobre o Grupo Caraça (Figura 7 seção A). Tanto $S_{0}$ quanto $S_{1}$ mostram homogeneidade de atitude com direção predominante NE-SW e mergulho para sudeste (Figura 6). Esse paralelismo reflete a geometria isoclinal a apertada das dobras $\mathrm{B}_{1}$. Os eixos dessas dobras são de baixo caimento e curvilíneos com sentido que varia entre NE, SE e SW. Em projeção estereográfica (Figura 6), a dispersão desses eixos aproxima-se de um grande círculo de direção NE-SW com mergulho para SE. Essa distribuição define um plano subparalelo à média das orientações da superfície $S_{1}$ e mostra o quão curvilíneo são os eixos $B_{1}$ (Figura 6).

As dobras $B_{2}$ possuem eixos com caimento suave a moderado entre os quadrantes SE e SW e a distribuição dos polos de $\mathrm{S}_{2}$ define uma guirlanda de direção NW-SE com eixo de dispersão 36/40 (Figura 6).

Ao longo do contato entre as formações Cauê e Cercadinho, ocorre zona de cisalhamento paralela ao acamamento. Essa zona de cisalhamento está desenvolvida sobre itabirito da Fm. Cauê e sua espessura é de poucos metros. O itabirito laminado da Fm. Cauê passa gradativamente à especularita xisto nas proximidades desse contato.

\section{Setor Central}

Tem direção N84E e toda a sequência do Sg. Minas também está invertida. No entanto, diferentemente do setor Oeste, a superfície de acamamento $\mathrm{S}_{0}$ das rochas dos grupos Caraça e da Fm. Cauê aflora com mergulhos elevados para SSE, enquanto as rochas das unidades superiores, que afloram na vertente norte da serra, apresentam mergulho suave a moderado também para SSE (Figura 7 - seção B). 

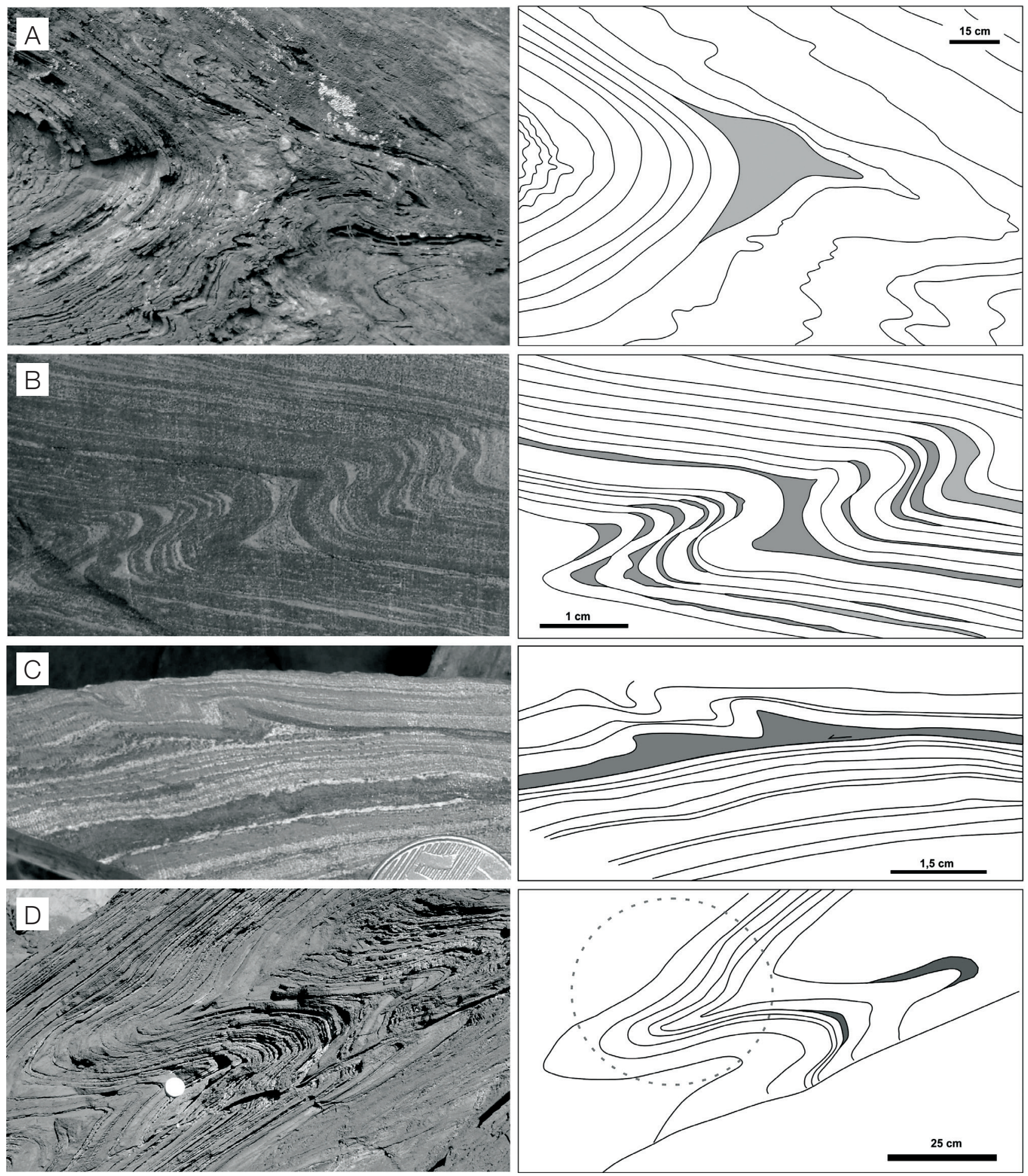

Figura 3. Exemplos de saddle reefs e charneira colapsada em dobras em itabirito quartzoso da Formação Cauê no segmento oeste da Serra do Curral. Nos croquis ao lado de cada foto, o preenchimento cinza indica saddle reef de quartzo. (A) Dobra desarmônica em afloramento na Mina Central; ( $\mathrm{B}$ e C) testemunho de sondagem na Mina Esperança; (D) antiforme com saddle reef de quartzo e sinforme com charneira colapsada (indicada pelo círculo pontilhado). Cava da Mina Oeste. 


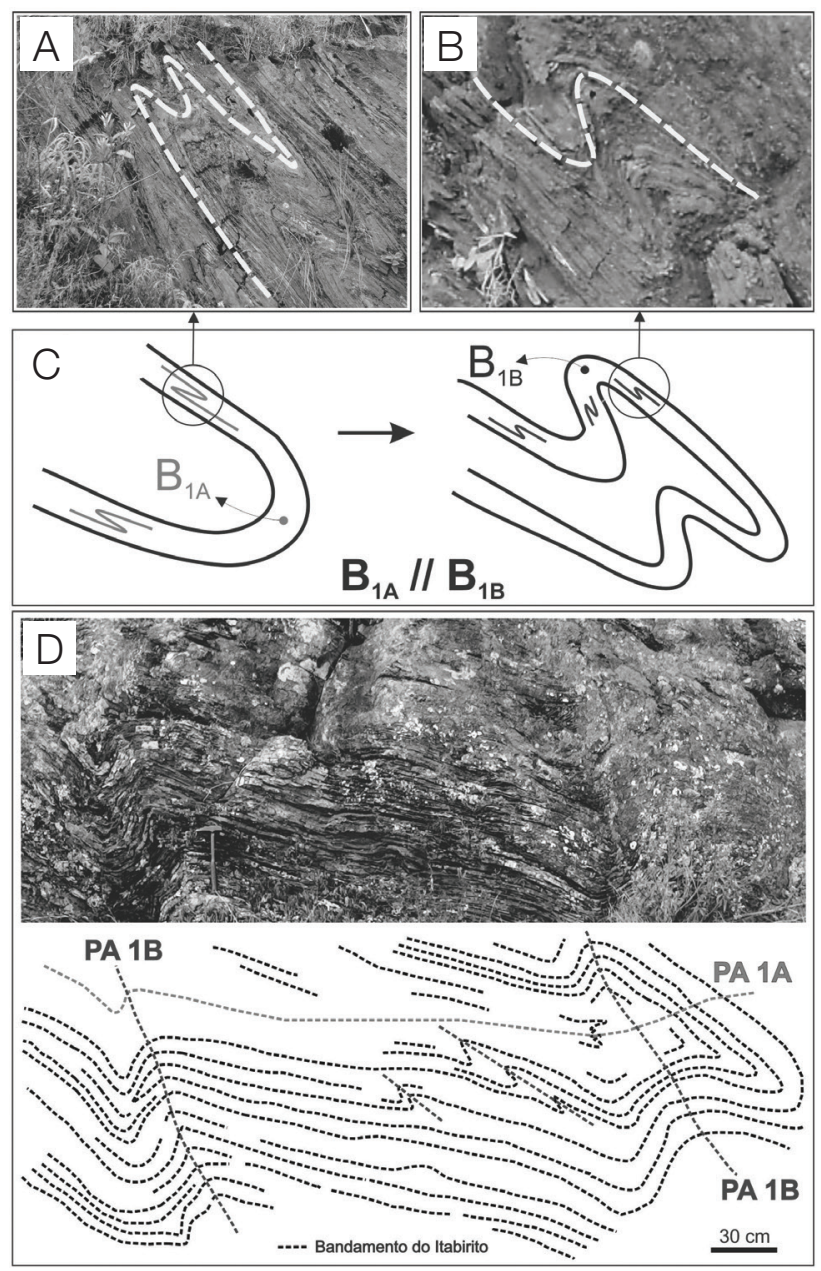

P1A: traço axial de dobra $B_{1 \mathrm{~A}}$; P1B: traço axial de dobra $\mathrm{B}_{1 \mathrm{~B}}$. Todas as imagens têm visada para leste.

Figura 4. (A) Exemplo de dobra $B_{1 A}$ com geometria " $Z$ " em itabirito - dobra parasítica de flanco invertido de dobra maior; (B) exemplo de dobra $B_{1 B}$ com geometria " $S$ " - dobra superposta à $B_{1 A}$. Tanto os eixos quanto os planos axiais de $B_{1 A}$ e $B_{1 B}$ são subparalelos; (C) desenho esquemático ilustrando a relação de superposição entre as dobras $B_{1 A} e$ $\mathrm{B}_{1 \mathrm{~B}}$; (D) fotografia (acima) e traços do bandamento itabirítico (abaixo) de afloramento de zona de charneira de dobra $\mathrm{B}_{1 \mathrm{~B}}$ onde é clara a relação de superposição com dobras $B_{1 A}$.

Em projeção estereográfica, os polos de $\mathrm{S}_{0}$ e $\mathrm{S}_{1}$ possuem distribuição semelhante, constituindo guirlandas de direção N-S com mergulho para W (Figura 6). Além dessa distribuição mais evidente, $\mathrm{S}_{1}$ também mostra discreta dispersão ao longo de um grande círculo de direção E-W com eixo de distribuição de caimento suave para $\mathrm{S}$. Os eixos das dobras $\mathrm{B}_{1}$ possuem caimento suave entre as direções ENE e ESE com máximo para E, enquanto os das dobras $\mathrm{B}_{2}$ são sub-horizontais, com caimento para SSE e NNW (Figura 6).

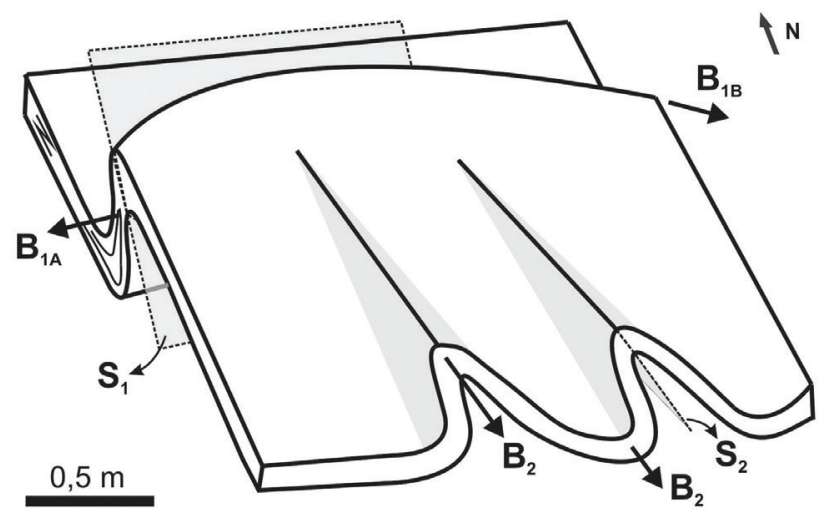

$\mathrm{S}_{1}$ e $\mathrm{S}_{2}$ : plano axial de $\mathrm{B}_{1}$ e $\mathrm{B}_{2}$, respectivamente.

Figura 5. llustração da ocorrência das abutting folds dobras $B_{2}$ com vergência para WSW, desenvolvidas no flanco de dobra $B_{1}$, confinando e desaparecendo contra sua charneira.

Nesse setor, $\mathrm{S}_{2}$ possui atitude homogênea, com mergulho de aproximadamente $55^{\circ}$ para E e ESE (Figura 6).

A zona de cisalhamento do contato entre as formações Cauê e Cercadinho também está presente neste setor. Situação semelhante é verificada em afloramento do contato do Grupo Nova Lima com o Grupo Caraça nas proximidades de Camargos. Nesse local, o quartzito com estruturas primárias preservadas da base da Fm. Moeda passa a quartzo mica-xisto com foliação anastomosada e lineação mineral marcada pela orientação de mica branca e grãos de quartzo alongados na direção do mergulho da xistosidade.

\section{Setor Leste}

É marcado pela orientação N55E da serra e a Fm. Moeda está, em parte da vertente sudeste, em contato com o Grupo Nova Lima e, em outra, em contato com granitoide do complexo granito-gnáissico Bonfim. Enquanto nos setores Oeste e Central o Grupo Nova Lima ocorre ao longo de toda a vertente sul da serra, neste setor ele se acunha para nordeste entre o complexo cristalino e o Sg. Minas até as proximidades da Mina Esperança (Figura 6). O contato dos granitoides com a Fm. Moeda é um zona de cisalhamento normal com mergulho de aproximandamente $75^{\circ}$ para NNW.

Neste setor, as unidades basais do Sg. Minas não estão invertidas e suas camadas possuem mergulho íngime (ca. $70^{\circ}$ ) para NW (Figura 7 - seção C). As unidades superiores, à semelhança dos outros setores, estão invertidas e mergulham para SE.

A superfície $\mathrm{S}_{0}$ mergulha predominantemente para $\mathrm{SE}$ e NW, configurando dispersão de polos em guirlanda de direção NW-SE (Figura 6) com eixo de dispersão 60/25. 


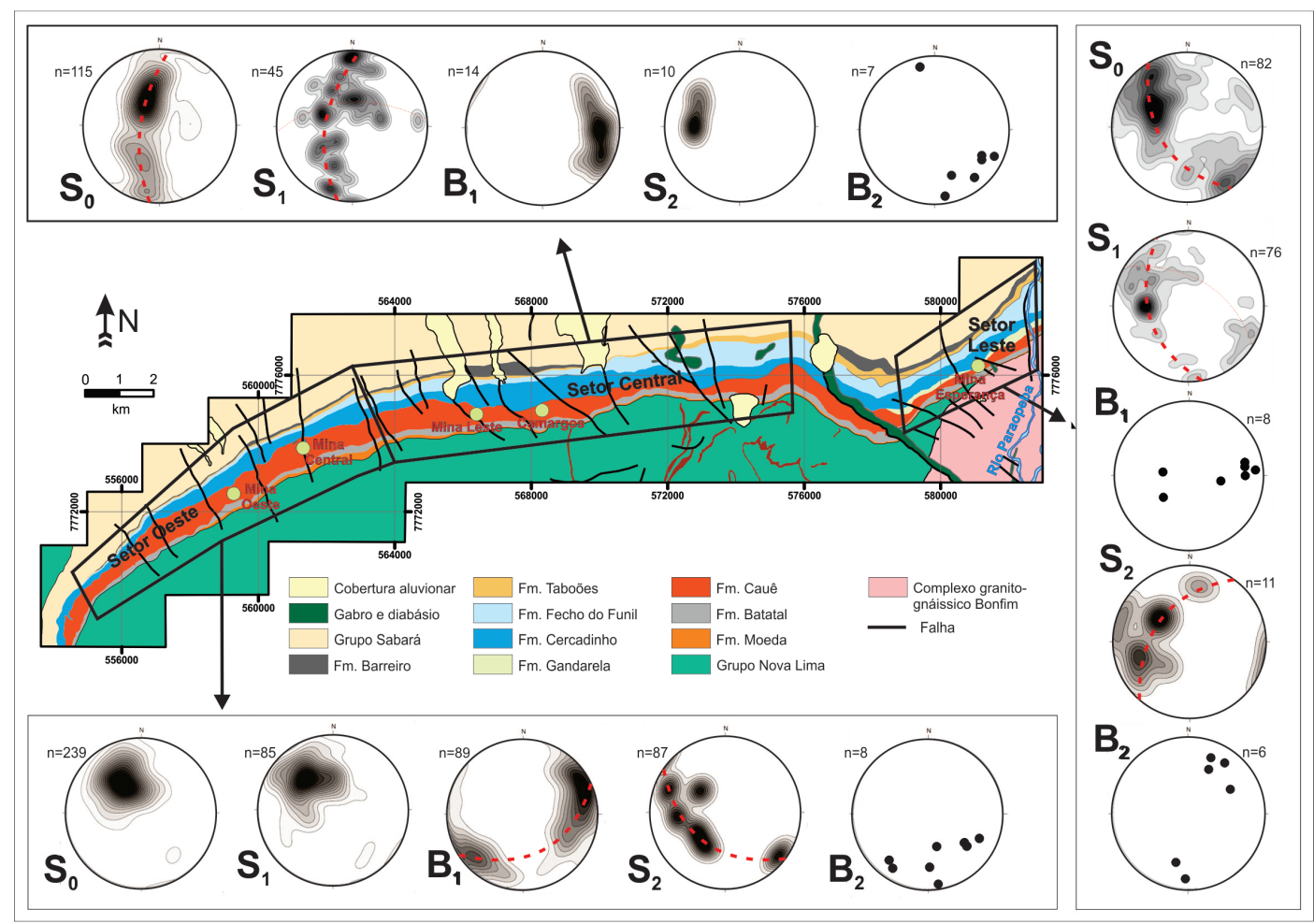

Figura 6. Mapa geológico-estrutural do segmento oeste da Serra do Curral com estereogramas (hemisfério inferior) dos polos de $S_{0}, S_{1}, S_{2}$ e dos eixos de dobras $B_{1}$ e $B_{2}$ dos setores Oeste, Central e Leste. A localização das minas Oeste, Central, Leste, Esperança e da área de Camargos também está indicada.
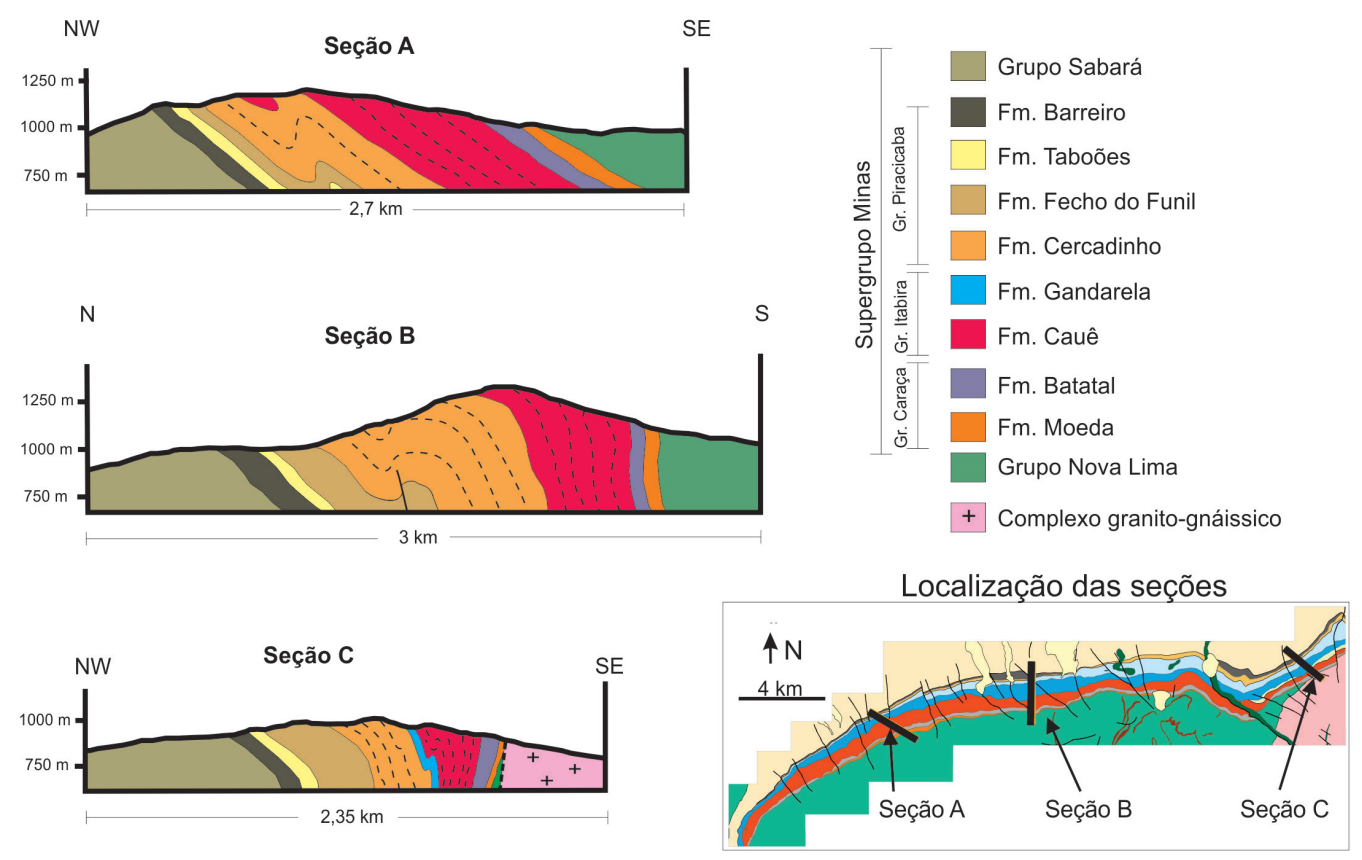

Gr: Grupo.

Figura 7. Seções geológicas verticais representativas dos setores Oeste (seção A), Central (seção B) e Leste (seção C) no segmento oeste da Serra do Curral. 
De modo semelhante, a foliação $S$ também mostra mergulho mais frequente para ESE e, de maneira mais sutil, mostra dispersão ao longo de duas guirlandas, uma de direção NNW com polo 78/50 e outra mais discreta com direção NW-SE com polo 211/27.

Os eixos das dobras $B_{1}$ têm direção geral ENE-WSW e possuem caimento mais suave para $\mathrm{E}$ do que para $\mathrm{W}$. Os eixos das dobras $\mathrm{B}_{2}$ mostram caimento suave a moderado para SSW e NE e os planos $\mathrm{S}_{2}$ mostram dispersão em grande círculo com polo 130/42.

\section{CONTROLE ESTRUTURAL DA MINERALIZAÇÃO DE FERRO}

As ocorrências de corpos magnetíticos-martíticos de alto teor que ocorrem ao longo do segmento oeste da Serra do Curral estão diretamente relacionadas às estruturas $\mathrm{B}_{1 \mathrm{~A}} \mathrm{e}$ $\mathrm{B}_{1 \mathrm{~B}}$ em sua região de charneira, em zonas de cisalhamento ou em falhas inversas de alto ângulo formadas contemporaneamente às dobras. A maior das acumulações ocorre no setor Leste e é explotada como minério de ferro na Mina Esperança. Esse corpo de minério possui direção NE-SW e geometria em cunha subvertical que se estreita em profundidade. Ele ocorre acima de falha inversa de alto ângulo e marca a passagem da região onde as camadas das rochas do setor leste mergulham para NW em posição normal para aquelas invertidas que mergulham para SE (Figuras $8 \mathrm{~A}$ e $8 \mathrm{~B}$ ). Essa acumulação é maciça (Figura 9A) ou com bandamento herdado do itabirito (Figura 9B). Do corpo principal originam-se apófises magnetítica-martíticas que se alojam em sucessão de filito e quartzito da Fm. Cercadinho (Figura 9C).

No restante da serra, embora não se tenha noticiado a ocorrência de corpos compactos de alto teor em ferro comparáveis ao da Mina Esperança em tamanho, ocorrem inúmeros veios magnetíticos-martíticos maciços, centimétricos a métricos, alojados tanto na Fm. Cauê quanto nas rochas do Grupo Piracicaba (Figura 9D). Também é comum, ao longo dos setores Central e Oeste, a ocorrência de brechas itabiríticas cimentadas por magnetita, martitizada ou não, em zonas de charneira de dobras $\mathrm{B}_{1}$ ou sem controle estrutural aparente (Figura 9E).

Outra forma de acumulação de alto teor em ferro é o especularita xisto. Esse tipo de rocha ocorre no topo estratigráfico da Fm. Cauê na área de influência da zona de cisalhamento situada ao longo do contato dessa unidade com a Fm. Cercadinho nos setores Oeste e Central. Nessa rocha, cristais de magnetita martitizada ocorrem como "porfiroclastos" envolvidos por especularita (Figura 9F) de forma semelhante à descrita por Rosière et al. (2013a). Esses autores interpretam essa estrutura como zona de cisalhamento com intensa circulação de fluidos.
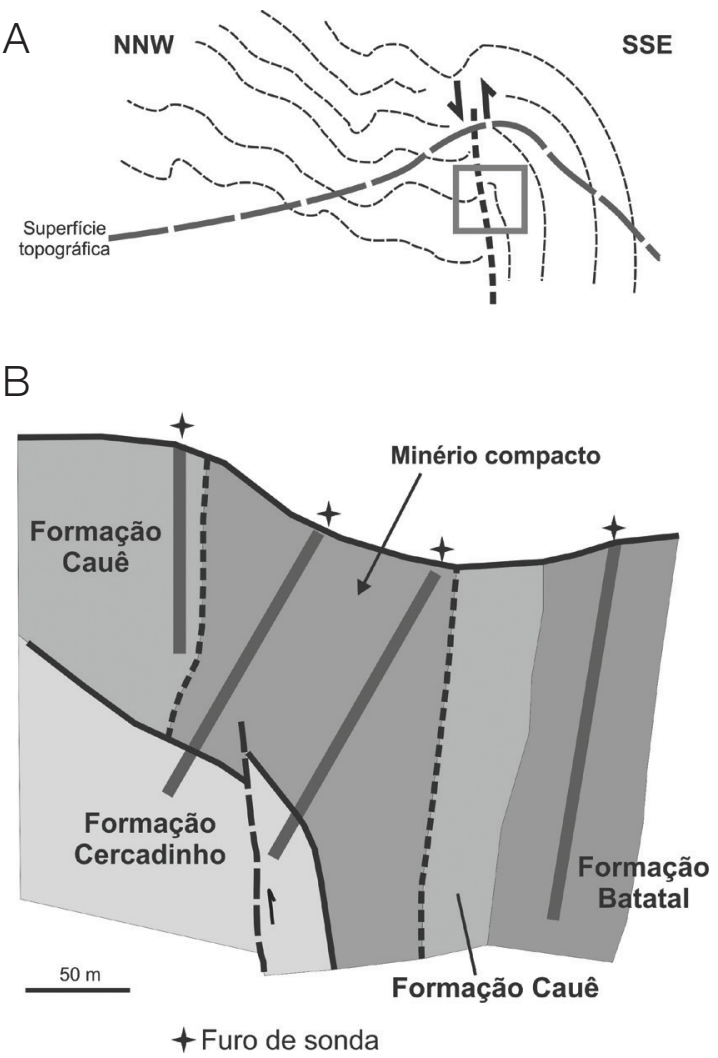

Figura 8. (A) Seção vertical esquemática da Serra do Curral na região da Mina Esperança; (B) seção vertical em detalhe mostrando a geometria em cunha do corpo de minério da Mina Esperança e seu condicionamento estrutural.

\section{Datação das acumulações compactas de alto teor em ferro}

Grãos de monazita de uma amostra de magnetitito martitizado com $96,4 \%$ de $\mathrm{Fe}_{2} \mathrm{O}_{3}$, hospedado por itabirito quartzoso da Fm. Cauê, foram analisados pelo método U/Pb SHRIMP (Sensitive High Resolution Ion Microprobe) no Laboratório de Geocronologia da Curtin University, Austrália (Rosière et al., 2013b). As incertezas de idades individuais foram cotadas a $1 \sigma$, enquanto que a idade dos plots foram calculadas no nível $2 \sigma$, com aproximadamente $95 \%$ de confiança (Tabela 1 ).

Nessa amostra, a monazita ocorre como mineral acessório e em equilíbrio textural com a magnetita martitizada (Figura 10A). O intercepto da discórdia no diagrama de concórdia retornou idade de $2034 \pm 11 \mathrm{Ma}$ (Figura 10B).

O resultado de $2034 \pm 11$ Ma é entendido como a idade de cristalização da monazita bem como da formação do corpo de alto teor em ferro que a contém. Segundo Pires (1995), a temperatura estimada para o metamorfismo da Fm. Cauê no segmento oeste da Serra do Curral está entre 300 e $400^{\circ} \mathrm{C}$, que é inferior à temperatura de bloqueio da monazita $\left(600 \pm 50^{\circ} \mathrm{C}\right.$, segundo Heaman e Parrish, 1991). 

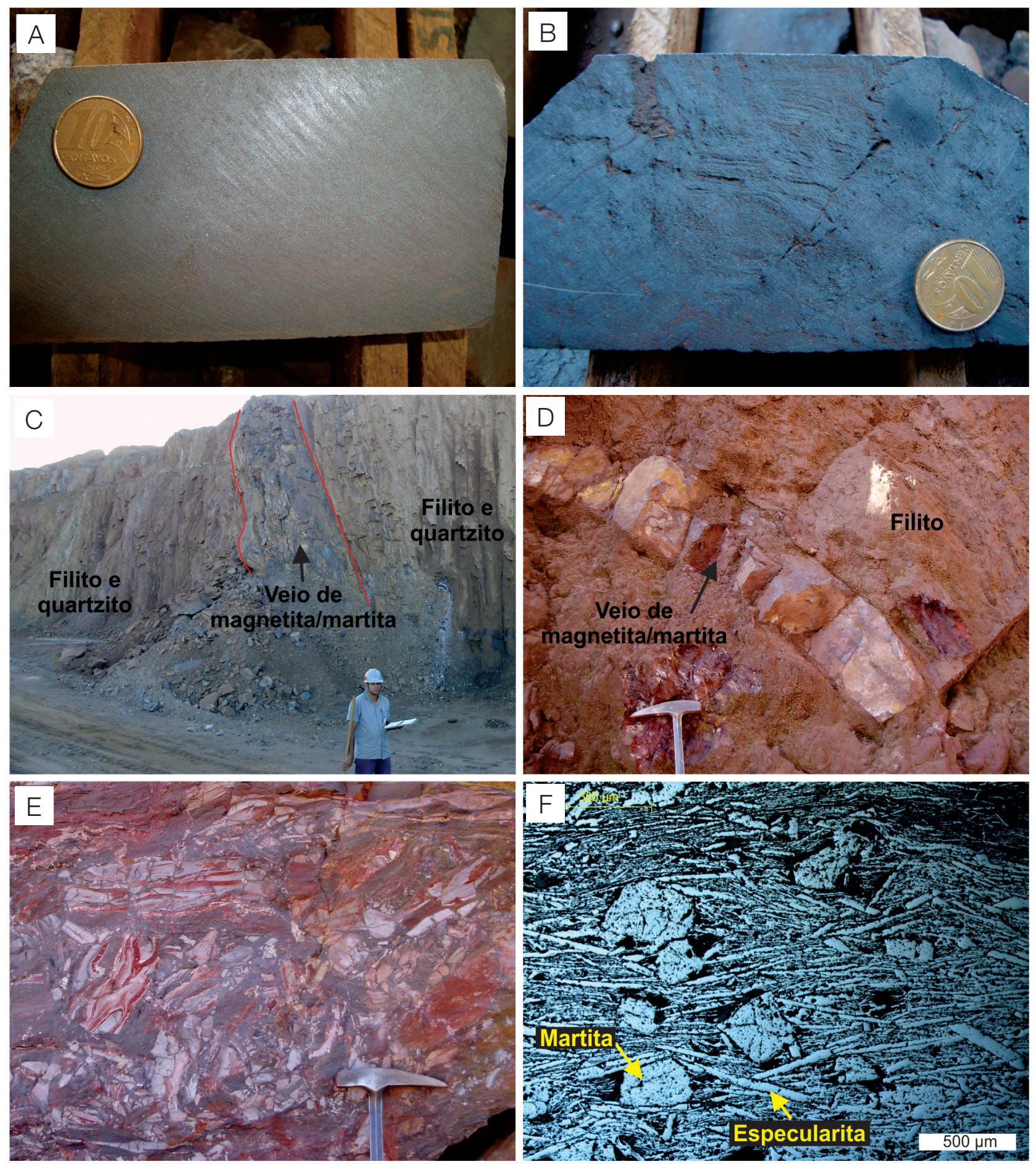

Figura 9. (A) Amostra de minério de alto teor maciço em testemunho de sondagem da Mina de Esperança; (B) amostra de minério de alto teor com bandamento herdado de itabirito em testemunho de sondagem da Mina de Esperança; (C) apófise magnetítica-martítica em intercalação de filito e quartzito da Fm. Cercadinho na cava da Mina Esperança; (D) veio magnetítico/martítico maciço em filito da Fm. Cercadinho na cava da Mina Leste; (E) itabirito quartzoso brechado com cimento magnetítico-martítico. Cava da Mina Central; (F) fotomicrografia sob luz refletida não polarizada de especularita xisto que ocorre em zona de cisalhamento no contato da Fm. Cauê com a Fm. Cercadinho. As lamelas especularíticas contornam os cristais de martita. Local: Mina Oeste. 
Tabela 1. Dados isotópicos U-Pb SHRIMP de monazite de magnetitito martitizado (mount UWA 12-14).

\begin{tabular}{|c|c|c|c|c|c|c|c|c|c|c|c|c|}
\hline \multirow{3}{*}{ Spot } & \multirow{3}{*}{$\begin{array}{c}\text { U } \\
\text { ppm }\end{array}$} & \multirow{3}{*}{$\begin{array}{l}\text { Th } \\
\text { U }\end{array}$} & \multirow{3}{*}{$\begin{array}{c}\mathrm{Pb} \\
\mathrm{ppm}\end{array}$} & \multirow{3}{*}{$\begin{array}{c}4 f 206 \\
(\%)\end{array}$} & \multicolumn{4}{|c|}{ Razões isotópicas } & \multicolumn{2}{|c|}{ Idades } & \multirow{3}{*}{$\begin{array}{l}\text { Erro de } \\
\text { correlação }\end{array}$} & \multirow{3}{*}{$\begin{array}{c}\text { Disc. } \\
\%\end{array}$} \\
\hline & & & & & ${ }^{207} \mathrm{~Pb}$ & ${ }^{207} \mathrm{~Pb}$ & ${ }^{206} \mathrm{~Pb}$ & ${ }^{208} \mathrm{~Pb}$ & ${ }^{206} \mathrm{~Pb}$ & ${ }^{207} \mathrm{~Pb}$ & & \\
\hline & & & & & ${ }^{206} \mathrm{~Pb}$ & ${ }^{235} \mathrm{U}$ & ${ }^{238} \mathrm{U}$ & ${ }^{232} \mathrm{Th}$ & ${ }^{238} \mathrm{U}$ & ${ }^{206} \mathrm{~Pb}$ & & \\
\hline A. 1 & 154 & 3270 & 21 & 0,32 & $0,12480 \pm 0,90$ & $5,7826 \pm 3,27$ & $0,3360 \pm 3,13$ & $0,0359 \pm 3,11$ & $1879 \pm 55$ & $2026 \pm 16$ & 0,959 & 7,8 \\
\hline A.2 & 77 & 4500 & 59 & 0,61 & $0,12252 \pm 1,56$ & $5,1808 \pm 2,06$ & $0,3067 \pm 1,33$ & $0,0416 \pm 3,38$ & $1756 \pm 24$ & $1993 \pm 28$ & 0,645 & 13,5 \\
\hline A.3 & 162 & 3550 & 22 & 0,31 & $0,12474 \pm 0,83$ & $6,4467 \pm 1,91$ & $0,3748 \pm 1,70$ & $0,0494 \pm 3,72$ & $2052 \pm 30$ & $2025 \pm 15$ & 0,892 & $-1,3$ \\
\hline$A-5$ & 249 & 3247 & 13 & 0,23 & $0,12392 \pm 1,03$ & $5,5150 \pm 2,18$ & $0,3228 \pm 1,90$ & $0,0520 \pm 3,42$ & $1824 \pm 34$ & $2013 \pm 18$ & 0,873 & 10,4 \\
\hline B-1 & 200 & 4078 & 20 & 0,40 & $0,12497 \pm 0,82$ & $5,9542 \pm 1,72$ & $0,3456 \pm 1,49$ & $0,1046 \pm 1,03$ & $1919 \pm 26$ & $2028 \pm 14$ & 0,867 & 5,7 \\
\hline$C-1$ & 108 & 1961 & 18 & 0,15 & $0,17542 \pm 0,67$ & $11,6094 \pm 2,83$ & $0,4800 \pm 2,74$ & $0,1389 \pm 1,33$ & $2529 \pm 46$ & $2610 \pm 11$ & 0,968 & 3,2 \\
\hline D-1 & 153 & 1846 & 12 & 0,44 & $0,12592 \pm 0,96$ & $6,7229 \pm 1,82$ & $0,3872 \pm 1,52$ & $0,1099 \pm 1,06$ & $2109 \pm 27$ & $2042 \pm 17$ & 0,839 & $-3,3$ \\
\hline$E-1$ & 81 & 5929 & 73 & 0,96 & $0,12452 \pm 1,85$ & $5,2958 \pm 2,74$ & $0,3085 \pm 2,01$ & $0,0293 \pm 1,32$ & $1769 \pm 36$ & $2022 \pm 33$ & 0,733 & 14,3 \\
\hline$E-2$ & 390 & 1930 & 5 & 0,26 & $0,12620 \pm 0,89$ & $6,4398 \pm 2,01$ & $0,3701 \pm 1,79$ & $0,0816 \pm 1,48$ & $2030 \pm 32$ & $2046 \pm 16$ & 0,888 & 0,8 \\
\hline$F-1$ & 186 & 1439 & 8 & 0,40 & $0,12662 \pm 0,79$ & $5,9441 \pm 1,41$ & $0,3405 \pm 1,13$ & $0,0617 \pm 6,08$ & $1901 \pm 20$ & $2052 \pm 14$ & 0,807 & 7,9 \\
\hline$F-2$ & 199 & 2939 & 15 & 0,31 & $0,12335 \pm 0,90$ & $6,2860 \pm 1,84$ & $0,3696 \pm 1,59$ & $0,0554 \pm 2,58$ & $2027 \pm 28$ & $2005 \pm 16$ & 0,863 & $-1,1$ \\
\hline F-3 & 177 & 1744 & 10 & 0,25 & $0,12491 \pm 0,78$ & $6,2495 \pm 2,03$ & $0,3629 \pm 1,86$ & $0,0673 \pm 2,82$ & $1996 \pm 33$ & $2028 \pm 14$ & 0,916 & 1,6 \\
\hline$F-4$ & 523 & 2034 & 4 & 0,02 & $0,12599 \pm 0,36$ & $6,7240 \pm 1,36$ & $0,3871 \pm 1,29$ & $0,1094 \pm 1,16$ & $2110 \pm 23$ & $2043 \pm 6$ & 0,946 & $-3,3$ \\
\hline$F-5$ & 350 & 1059 & 3 & 0,02 & $0,12651 \pm 0,42$ & $6,8613 \pm 1,68$ & $0,3933 \pm 1,61$ & $0,0744 \pm 1,66$ & $2138 \pm 28$ & $2050 \pm 7$ & 0,957 & $-4,3$ \\
\hline F-6 & 178 & 3253 & 18 & 0,27 & $0,12293 \pm 0,78$ & $6,0328 \pm 1,96$ & $0,3559 \pm 1,78$ & $0,0707 \pm 1,48$ & $1964 \pm 32$ & $1999 \pm 14$ & 0,908 & 1,8 \\
\hline $\mathrm{F}-7$ & 208 & 3106 & 15 & 0,07 & $0,12660 \pm 0,59$ & $6,4527 \pm 1,84$ & $0,3697 \pm 1,73$ & $0,0496 \pm 1,51$ & $2029 \pm 31$ & $2051 \pm 10$ & 0,938 & 1,1 \\
\hline G-1 & 167 & 2374 & 14 & 0,63 & $0,12408 \pm 1,00$ & $6,0904 \pm 1,83$ & $0,3560 \pm 1,51$ & $0,0691 \pm 1,63$ & $1965 \pm 27$ & $2016 \pm 18$ & 0,827 & 2,6 \\
\hline
\end{tabular}

Erro das razões isotópicas estão em \%. Todo $\mathrm{Pb}$ nas razões é componente radiogênico corrigido para ${ }^{204} \mathrm{~Pb}$.

Disc.: discordância, como $100-100\left\{t\left[{ }^{206} \mathrm{~Pb} /{ }^{238} \mathrm{U}\right] / \mathrm{t}\left[{ }^{207} \mathrm{~Pb} /{ }^{206} \mathrm{~Pb}\right]\right\}$

$\mathrm{f} 206=\left({ }^{206} \mathrm{~Pb}\right.$ comum $) /\left({ }^{206} \mathrm{~Pb}\right.$ total medido) baseado no ${ }^{204} \mathrm{~Pb}$ medido

Incertezas são $1 \sigma$.
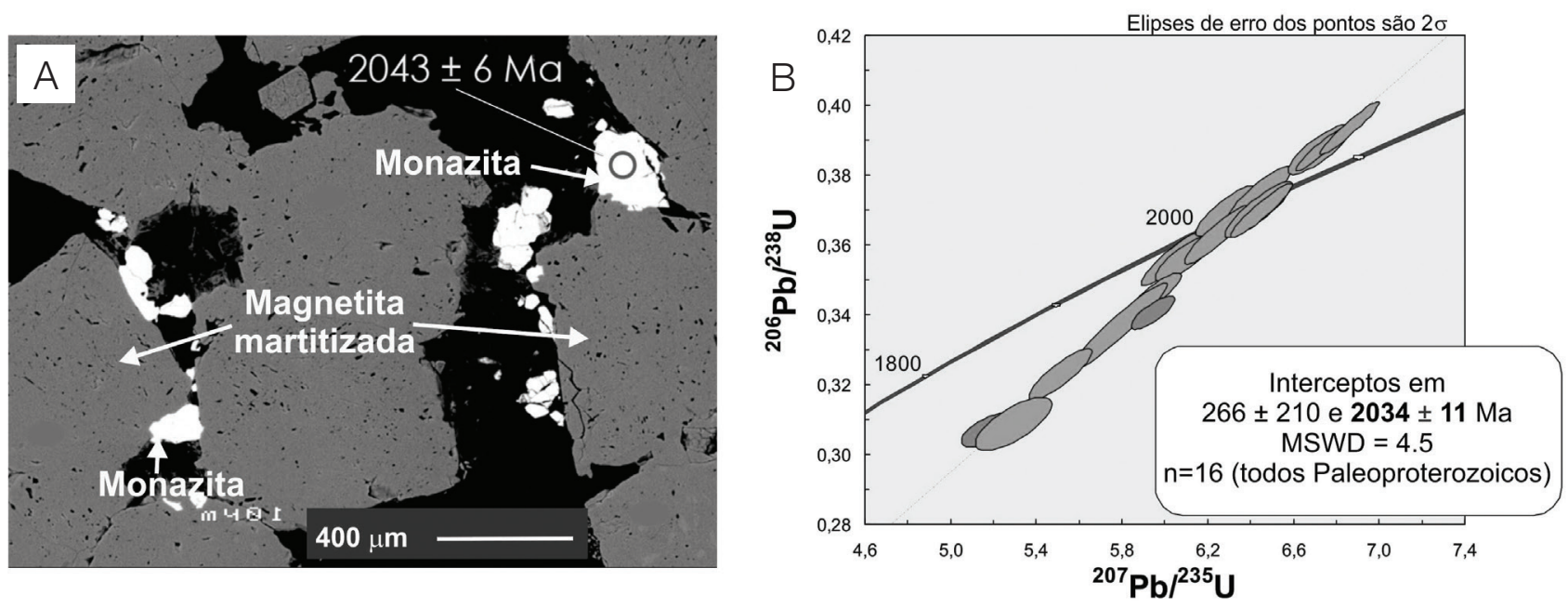

Figura 10. (A) Imagem de elétrons retroespalhados. Grão de monazita em equilíbrio textural com magnetita/martita e indicação da idade obtida em um dos 16 pontos analisados; (B) diagrama de concórdia dos grãos de monazita que ocorrem em equilíbrio textural com os óxidos de ferro de acumulação de alto teor. O intercepto da discórdia indica idade de cristalização da monazita em $2034 \pm 11$ Ma. 


\section{ANÁLISE E MODELO ESTRUTURAL}

Os estereogramas de polos de $\mathrm{S}_{0}$ e $\mathrm{S}_{1}$ do setor Oeste mostram uma concentração no quadrante NW que reflete o pequeno valor do ângulo interflancos das gerações de dobras $\mathrm{B}_{1 \mathrm{~A}}$ e $B_{1 B}$. Nos setores Central e Leste, os polos de $\mathrm{S}_{0}$ e $\mathrm{S}_{1}$ se distribuem em grandes círculos subparalelos de direção ortogonal ao trend da serra. $\mathrm{O}$ eixo de dispersão dessas guirlandas é paralelo aos eixos da dobra $\mathrm{B}_{1 \mathrm{~A}}$ e corresponde, portanto, aos eixos das dobras $\mathrm{B}_{1 \mathrm{~B}}$. Como as dobras $\mathrm{B}_{1 \mathrm{~A}}$ são isoclinais a apertadas, a distribuição de $S_{1}$ mostra o efeito do redobramento pelas dobras $\mathrm{B}_{1 \mathrm{~B}}$ do mesmo modo que $\mathrm{S}_{0} \mathrm{e}$, juntas, refletem a morfologia " $\mathrm{M}$ " das estruturas que ocorrem na zona de charneira.

A direção dos eixos $\mathrm{B}_{2}$ exibe uma relação de ortogonalidade ou alta obliquidade com a direção de $\mathrm{B}_{1}$ e seu caimento se dá para o mesmo quadrante do mergulho de $\mathrm{S}_{0}$ e $\mathrm{S}_{1}$ onde $\mathrm{B}_{2}$ se desenvolve. Os eixos da dispersão menos pronunciada de $S_{1}$ nos setores Central e Leste são subparalelos aos eixos $\mathrm{B}_{2}$.

A partir da integração dos dados estruturais dos diferentes setores discriminados aqui e da relação entre eles, entende-se que a progressiva variação do mergulho das camadas do Sg. Minas nos diferentes segmentos da Serra do Curral é condicionada aos diferentes níveis de exposição do Sinclinal Piedade ao longo da serra. Assim, de oeste para leste, há a uma gradativa transição de uma zona típica de flanco (o flanco invertido do sinclinal) para as proximidades da zona de charneira dessa estrutura na região da Mina Esperança (Figura 11).

As dobras $\mathrm{B}_{1 \mathrm{~A}}$ com indicação cinemática horária (padrão "Z" em visada para leste) são parasíticas do sinclinal vergente para NW e caracterizam o flanco invertido da estrutura regional, como já proposta por Alves (1961), Simmons (1968), Romano (1989), Pomerene (1964), Pires (1979), Alkmim et al. (1996) e Endo (1997). No entanto, as dobras $\mathrm{B}_{1 \mathrm{~B}}$ indicam movimentação reversa com topo para NNW e se sobrepõem às $B_{1 A}$. Essa superposição onde os elementos geométricos - plano axial e eixo - das dobras da segunda geração $\left(B_{1 B}\right)$ são subparalelos aos do dobramento anterior $\left(\mathrm{B}_{1 \mathrm{~A}}\right)$ indica que a deformação compressiva com vergência geral para NNW ocorreu em caráter progressivo com geração de dois acervos de dobras.

As zonas de cisalhamento que ocorrem ao longo dos contatos Grupo Nova Lima/Grupo Caraça e Grupo Itabira/ Grupo Piracicaba nos setores Oeste e Leste podem ser atribuídas ao deslizamento interestratal ou descolamento das diferentes unidades entre si durante a edificação das dobras $\mathrm{B}_{1 \mathrm{~A}}$ associadas às falhas de baixo ângulo. No deslizamento flexural, a deformação concentra-se nos flancos, decrescendo em direção à zona de charneira (Ramsay e Huber, 1987). Essa diminuição pode justificar a ausência dessas duas zonas de cisalhamento no setor Leste. Por outro lado, a acomodação da deformação contemporânea à superposição de $\mathrm{B}_{1 \mathrm{~B}}$ sobre $\mathrm{B}_{1 \mathrm{~A}}$ se dá principalmente como falhas inversas de alto ângulo na zona de charneira (setor Leste), enquanto no flanco (setor Oeste) há a geração efetiva de dobras fechadas a isoclinais. Essas falhas inversas podem se originar como alternativa à acomodação da deformação na zona de charneira, uma vez que esse domínio da dobra impõe resistência à superposição de dobras e, portanto, à geração de dobras $\mathrm{B}_{1 \mathrm{~B}}$. Em superposição de dobras por flambagem, as superfícies deformadas inicialmente não são dobradas passivamente e influenciam ativamente a geometria e a estrutura gerada na fase de deformação posterior (Simón, 2004). Por essa mesma razão, as dobras $\mathrm{B}_{2}$ que são ortogonais às $\mathrm{B}_{1} \mathrm{e}$ vergentes para $\mathrm{W}$ limitam-se aos flancos dessas últimas e desaparecem em direção às zonas de charneira das dobras $\mathrm{B}_{1} \mathrm{e}$, assim, $\mathrm{B}_{2}$ não provoca rotação dos eixos $\mathrm{B}_{1}$.

A distribuição dos polos de $\mathrm{S}_{2}$, entretanto, ocorre como diferentes guirlandas nos setores oeste e leste da Serra do Curral. Os eixos de dispersão dessas guirlandas são

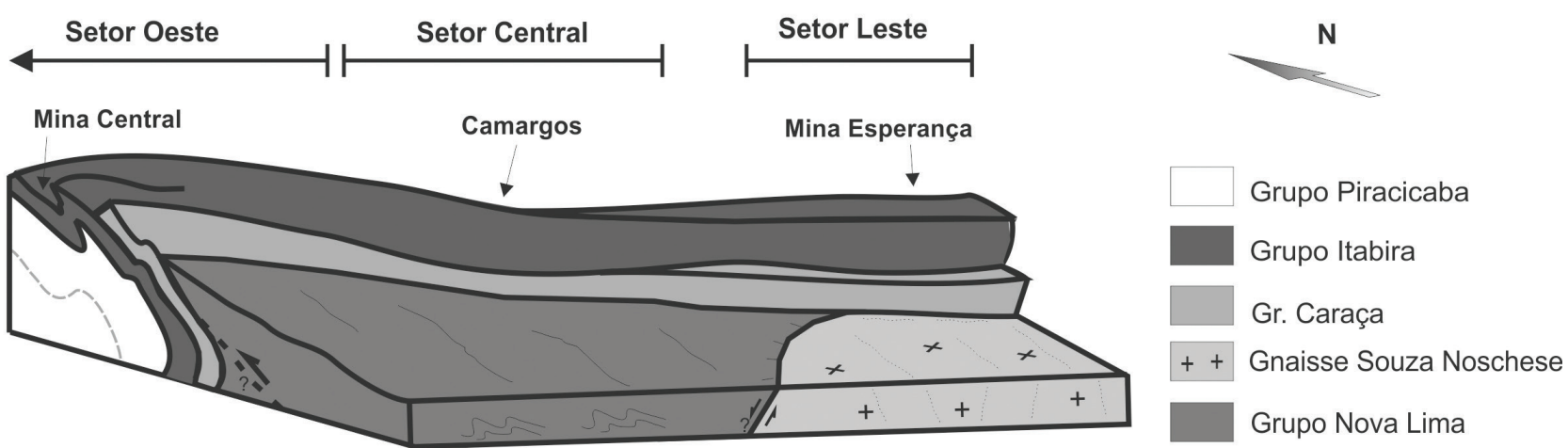

Figura 11. Bloco diagrama esquemático da estrutura do segmento oeste da Serra do Curral com a localização dos depósitos de ferro. 
subparalelos aos eixos $\mathrm{B}_{1 \mathrm{~B}}$ nesses setores, o que sugere uma penecontemporaneidade entre $\mathrm{B}_{1 \mathrm{~B}}$ e $\mathrm{B}_{2}$ e falhas associadas.

Dalstra e Rosière (2008) mostraram que, de maneira geral, as acumulações de alto teor em ferro de origem hipogênica em vários depósitos do QF estão controladas tanto por estruturas de natureza compressiva de direção NE-SW (e.g. Depósito de Águas Claras e Feijão) quanto por estruturas de direção NNW-SSE, como os depósitos da Mutuca, Tamanduá e os outros que também ocorrem no flanco leste do Sinclinal Moeda. Esses mesmos autores propuseram que os dois trends estruturais regionais estariam relacionados ao mesmo evento deformacional paleoproterozoico $\mathrm{e}$, segundo eles, o acervo de estruturas de trend NNW-SSE teria se desenvolvido após a nucleação das estruturas de direção geral NE-SW. Em comparação com o acervo estrutural descrito aqui para o segmento oeste da Serra do Curral, as dobras $B_{2}$ que se superpõem às estruturas de direção ENEWSW podem ser correlacionadas, então, às grandes estruturas de mesma direção que ocorrem regionalmente no $\mathrm{QF}$.

\section{CONCLUSÕES}

A análise estrutural no segmento oeste da Serra do Curral mostra que as estruturas vergentes para NNW desenvolveram-se em um evento polifásico durante a orogenia Transamazônica, como proposto por Alkmim e Marshak (1998), com a geração de dobras superpostas e falhas inversas sobre um sinclinal invertido de direção NNE-SSW vergente para NNW. As estruturas relacionadas a essa tectônica compressiva foram posteriormente superpostas por deformação vergente para oeste.

A primeira fase de deformação identificada no segmento oeste da Serra do Curral está associada ao desenvolvimento de dobras isoclinais e apertadas parasíticas ao Sinclinal Piedade $\left(\mathrm{B}_{1 \mathrm{~A}}\right)$ superpostas, em caráter de deformação progressiva, por dobras $\mathrm{B}_{1 \mathrm{~B}}$. Essa superposição manifesta-se de maneira diferenciada ao longo do sinclinal, com formação de dobras apertadas a isoclinais no setor Oeste e falhas inversas de alto ângulo no setor Leste. As acumulações compactas de alto teor em ferro dessa região, sejam magnetíticas-martíticas ou especularíticas, têm ocorrência controlada por essas estruturas.

A relação temporal entre os dois trends de estruturas compressivas descritos no segmento oeste da Serra do Curral é compatível com a relação das grandes estruturas do QF; esses trends podem ser atribuídos ao mesmo ciclo orogênico, quando, no foreland do orógeno paleoproterozoico, houve deformação com encurtamento nos quadrantes NW-SE e NE-SW, provavelmente com a participação dos domos gnássicos, produzindo a atual configuração quadrangular do $\mathrm{QF}$, anteriormente à fase de colapso postulada por Alkmim e Marshak (1998).
Datação U/Pb SHRIMP em monazita que ocorre em equilíbrio textural com magnetita-martita das acumulações de alto teor em ferro forneceu idade de $2034 \pm 11 \mathrm{Ma}$. Essa idade indica que o processo hipogênico responsável pela formação dos corpos de alto teor em ferro é contemporâneo ao pico metamórfico registrado para a região do $\mathrm{QF}$.

\section{AGRADECIMENTOS}

Os autores agradecem o apoio das equipes das minas da Usiminas e Ferrous Resources na Serra do Curral, particularmente aos geólogos V. Suckau e H. Meireles; agradecem também ao Conselho Nacional de Desenvolvimento Científico e Tecnológico ( $\mathrm{CNPq}$ ) pela concessão de suporte financeiro (Pr. 472602/2009-8) e pela manutenção da bolsa de mestrado para Julio Sanglard. Finalmente, agradecem a C.A. Ávila e L. Lagoeiro pelas críticas construtivas.

\section{REFERÊNCIAS}

Alkmim, F. F., Amorim, L. Q., Souza, K., Cavalcanti, J. A. D., Lanfranchi, R. A., Santos, J. H., Freitas, C. A., Oliveira, F. M., Barbosa, V. C. (1996). A Junção entre o Sinclinal da Moeda e o Homoclinal da Serra do Curral, Quadrilátero Ferrífero, MG. $39^{\circ}$ Congresso Brasileiro de Geologia, v. 1, 337-340. Salvador: SBG.

Alkmim, F. F., Marshak, S. (1998). Transamazonian orogeny in the Southern São Francisco Craton region, Minas Gerais, Brazil: evidence for Paleoproterozoic collision and collapse in Quadrilátero Ferrífero. Precambrian Research, 90, 29-58.

Almeida, F. F. M. (1977). O Cráton do São Francisco. Revista Brasileira de Geociências, 7, 349-364.

Alves, B. P. (1961). Sumário sobre estratigrafia e estrutura das quadrículas de Caeté e Serra da Piedade. Publicação da Sociedade de Intercâmbio Cultural e Estudos Geológicos, 1, 257-260. Ouro Preto: SICEG.

Ávila, C. A., Teixeira, W., Vasques, F. S. G., Dussin, I. A., Mendes, J. C. (2012). Geoquímica e Idade U-Pb (LA-ICPMS) da Crosta Oceânica Riaciana do Cinturão Mineiro, Borda Meridional do Cráton do São Francisco. $46^{\circ}$ Congresso Brasileiro de Geologia. Mídia eletrônica... Santos: SBG.

Babinski, M., Chemale Jr., F., Van Schmus, W. R. (1995). $\mathrm{The} \mathrm{Pb} / \mathrm{Pb}$ age of the Minas Supergroup carbonate rocks, Quadrilátero Ferríffero, Brazil. Precambrian Research, 72, 235-245. 
Barbosa, A. L. M. (1968). Contribuições recentes à geologia do Quadrilátero Ferrífero. Belo Horizonte: SBG-MG. Reimpressão (1985): UFMG, Instituto de Geociências, Departamento de Geologia.

Carneiro, M. A. (1992). O Complexo Metamórfico Bonfim Setentrional (Quadrilátero Ferrifero - Minas Gerais): litoestratigrafia e evolução geológica de um segmento de crosta continental do arqueano. Tese (Doutorado). São Paulo: Instituto de Geociências - USP.

Carneiro, M. A., Teixeira, W., Carvalho Junior, I. M., Fernandes, R. A. (1998). Ensialic tectonic setting of the archaean Rio das Velhas Greenstone Belt: $\mathrm{Nd}$ and $\mathrm{Pb}$ isotopic evidence from Bonfim Metamorphic Complex, Quadrilátero Ferrífero, Brazil. Revista Brasileira de Geociências, 28(2), 189-200.

Chemale Jr., F., Rosière, C. A., Endo, I. (1994). The tectonic evolution of the Quadrilátero Ferrífero, Minas Gerais. Precambrian Research, 65, 25-54.

Dalstra, H. J., Rosière, C. A. (2008). Structural controls on high-grade iron ores hosted by bandaded iron formations: a global perspective. Reviews in Economic Geology, 15, 73-106.

Dorr II, J. V. N., Gair, J. E., Pomerene, J. B., Rynearson, G. A. (1957). Revisão da estratigrafia pré-cambriana do Quadrilátero Ferrífero, Brasil. Avulso DNPM/DFPM, v. 81.

Dorr II, J. V. N. (1958a). The Cauê Itabirite. Boletim da Sociedade Brasileira de Geologia, 2(7), 61-62.

Dorr II, J. V. N. (1958b). The Gandarela Formation. Boletim da Sociedade Brasileira de Geologia, 2(7), 63-64.

Dorr II, J. V. N. (1969). Physiographic, stratigraphic and structural development of the Quadrilátero Ferrífero, Minas Gerais, Brazil. USGS Professional Paper, 641-A, 1-110.

Endo, I. (1997). Regimes tectônicos do Arqueano e Proterozóico no interior da placa Sanfranciscana: Quadrilátero Ferrífero e áreas adjacentes, Minas Gerais. Tese (Doutorado). São Paulo: Instituto de Geociências - USP.

Endo, I., Machado, R. (2002). Reavaliação e novos dados geocronológicos $(\mathrm{Pb} / \mathrm{Pb}$ e K/Ar) da região do Quadrilátero Ferrífero e adjacências. Geologia USP: Série Científica, 2, 23-40.

Gair, J. E. (1958). The Sabará Formation. Boletim da Sociedade Brasileira de Geologia, 2(7), 68-69.
Heaman, L., Parrish, R. (1991). U-Pb Geochronology of Accessory Minerals. In: L. Heaman, J. N. Ludden (Eds.), Applications of Radiogenic Isotope Systems to Problems in Geology. Québec: Mineralogical Association of Canada.

Herz, N. (1978). Metamorphic rocks of the Quadrilátero Ferrífero, Minas Gerais, Brazil. USGS Professional Paper, 641-C, 1-81.

Hippertt, J., Davis, B. (2000). Dome emplacement and syncline development in a granite-greenstone terrain (Quadrilátero Ferrífero, southeastern Brazil). Precambrian Research, $102,99-121$.

Jordt-Evangelista, H., Alkmim, F., Marshak, S. (1992). Metamorfismo progressivo e a ocorrência de três polimorfos de $\mathrm{Al}_{2} \mathrm{SiO}_{5}$ na Formação Sabará, Ibirité, Quadrilátero Ferrífero, MG. Revista da Escola de Minas, 45, 157-160.

Ladeira, E. A., Viveiros, J. F. M. (1984). Hipótese sobre a estruturação do Quadrilátero Ferrífero com base nos dados disponíveis. Boletim da Sociedade Brasileira de Geologia, $4,1-14$.

Loczy, L., Ladeira, E. A. (1976). Geologia Estrutural e Introdução à Geotectônica. São Paulo: Edgar Blücher.

Machado, N., Noce, C. M., Ladeira, E. A., Belo de Oliveira, A. O. (1992). U-Pb geochronology of Archean magmatism and Proterozoic metamorphism in the Quadrilátero Ferrífero, southern São Francisco Cráton, Brazil. Geological Society American Bulletin, 104, 1221-1227.

Marshak, S., Tinkham, D., Alkmim, F. F., Brueckner, H., Bornhorst, T. (1997). Dome-and-keel provinces formed during Paleoproterozoic orogenic collapse - Diapir clusters, core complexes, or neither? Examples from the Quadrilátero Ferrifero (Brazil) and the Penokean Orogen (USA). Geology, 25, 415-418.

Maxwell, C. H. (1958). The Batatal Formation. Boletim da Sociedade Brasileira de Geologia, 2(7), 60-61.

Noce, C. M. (2000). Geochronology of the Quadrilátero Ferrífero: a review. Geonomos, 8(1), 15-23.

Noce, C. M., Machado, N., Teixeira, W. (1998). $\mathrm{U}-\mathrm{Pb}$ geochronology of gneisses and granitoids in the Quadrilátero Ferrífero (southern São Francisco craton): age constraints for Archean and Paleoproterozoic magmatism and metamorphism. Revista Brasileira de Geociências, 28(1), 95-102. 
Pflug, R., Renger, F. (1973). Estratigrafia e evolução geológica da margem SE do Cráton do São Francisco. $27^{\circ}$ Congresso Brasileiro de Geologia, 5-19. Aracajú: SBG.

Pires, F. R. M. (1995). Textural and mineralogical variations during metamorphism of the Proterozoic Itabira Iron Formation in the Quadrilátero Ferrífero, Minas Gerais, Brazil. Anais da Academia Brasileira de Ciências, 67(1), 77-105.

Pires, F. R. M. (1979). Structural geology and stratigraphy at the junction of the Curral Anticline and Moeda Syncline. Tese (Doutorado). Michigan: Michigan Technological University.

Pomerene, J. B. (1958a). The Cercadinho Formation. Boletim da Sociedade Brasileira de Geologia, 2(7), 64-65.

Pomerene, J. B. (1958b). The Taboões Quartzite. Boletim da Sociedade Brasileira de Geologia, 2(7), 66-67.

Pomerene, J. B. (1958c). The Barreiro Formation. Boletim da Sociedade Brasileira de Geologia, 2(7), 67-68.

Pomerene, J. B. (1964). The geology and ore deposits of the Belo Horizonte, Ibirité and Macacos quadrangles, Minas Gerais, Brazil. USGS Professional Paper, 341-5, 1-84.

Ramsay, J. G. (1967). Folding and fracturing of rocks. New York: McGraw-Hill Book Company.

Ramsay, J. G., Huber, M. I. (1987). The Techniques of Modern Structural Geology 2: folds and fractures. London: Academic Press.

Renger, F. S., Noce, C. M., Romano, A. W., Machado, N. (1994). Evolução sedimentar do Supergrupo Minas: 500 Ma de registro geológico no Quadrilátero Ferrífero, Minas Gerais, Brasil. Geonomos, 2(1), 1-11.

Romano, A. W. (1989). Evolution Tectonique de la region nord-ouest du Quadrilatère Ferrifère-Minas Gerais - Brésil. Tese (Doutorado). Nancy: Université de Nancy.
Rosière, C. A., Garcia, O. L., Siemes, H., Schaeben, H. (2013a). Domainal fabrics of hematite in schistose, shear zone-hosted highgrade Fe ores: the product of the interplay between deformation and mineralization. Journal of Structural Geology, 55, 150-166.

Rosière, C. A., Sanglard, J. C. D., Sabadini Jr., R., Hensler, A. S., Hagemann, S., Santos, J. O. S., McNaughton, N., Fletcher, I. (2013b). Iron mineralization in the Quadrilátero Ferrífero: structural control, age and mineral-chemical changes. $12^{\text {th }}$ SGA Biennial Meeting - Mineral Deposit Research for a High-Tech World. Uppsala: SGA.

Rosière, C. A., Siemes, H., Quade, H., Brokmeier, H. G., Jansen, E. M. (2001). Microstructures, textures and deformation mechanisms in hematite. Journal of Structural Geology, 23, 1429-1440.

Rosière, C. A., Spier, C. A., Rios, F. J., Suckau, V. E. (2008). The itabirites of the Quadrilátero Ferrífero and related highgrade iron ore deposits: an overview. Reviews in Economic Geology, 15, 223-254.

Simmons, G. C. (1968). Geology and iron deposits of the western Serra do Curral, Minas Gerais, Brazil. USGS Professional Paper, 341-G, 1-58.

Simón, J. L. (2004). Superposed buckle folding in the eastern Iberian Chain, Spain. Journal of Structural Geology, 26, 1447-1464.

Spier, C. A., Oliveira, S. M. B., Rosière, C. A., Ardisson, J. D. (2008). Mineralogy and trace-element geochemistry of the highgrade iron ores of the Águas Claras Mine and comparison with the Capão Xavier and Tamanduá iron ore deposits, Quadrilátero Ferrífero, Brazil. Mineralium Deposita, 43, 229-254.

Teixeira, W., Carneiro, M. A., Noce, C. M., Machado, N., Sato, K., Taylor, P. N. (1996). Pb, Sr and Nd isotope constraints on the Archean evolution of gneissic-granitoid complexes in the southern São Francisco craton, Brazil. Precambrian Research, 78, 151-164.

Wallace, R. M. (1958). The Moeda Formation. Boletim da Sociedade Brasileira de Geologia, 2(7), 59-60. 